\title{
Optimal forecast algorithm based on compatible linear filtration and extrapolation
}

\author{
Mashkov O. A. ${ }^{1}$, Murasov R. K. ${ }^{2}$, Kravchenko Y. V. ${ }^{2}$, \\ Dakhno N. B. ${ }^{2}$, Leschenko O. A. ${ }^{2}$, Trush A. V. ${ }^{2}$ \\ ${ }^{1}$ State Ecological Academy of Postgraduate Education and Management, \\ 35 Metropolitan Vasyl Lipkivsky Str., build. 2, 03035, Kyiv, Ukraine \\ ${ }^{2}$ Taras Shevchenko National University of Kyiv, \\ 24 Bogdan Gavrilishin Str., 04116, Kyiv, Ukraine,
}

(Received 7 April 2020; Revised 12 March 2021; Accepted 17 March 2021)

\begin{abstract}
This work considers the methods of optimal linear extrapolation of the flight path of the aircraft, which provide a minimum of the mean square of the forecast error with different amounts of a priori information. The research is based on the canonical decomposition of a vectorial random process. It is determined that the development of modern technologies entails increasing requirements for quality and accuracy of control. However, since the existing methods of linear extrapolation do not provide for the maximum accuracy of the forecast due to the inherent constraints on the random process that describe the motion of aircraft, this necessitates a further development and improvement of methods for extrapolation of aircraft trajectories. The peculiarity of the developed methods for extrapolation of aircraft trajectory is that they allow within the correlation model to fully take into account the properties of a real random process that describes the motion of aircraft at the landing approach stage. This provides for the maximum possible accuracy of linear extrapolation with a variety of information support conditions. These methods allow improving the safety of flights and the efficiency of aviation. Accordingly, new capabilities of aircraft and other sophisticated technical systems can be further considered.
\end{abstract}

Keywords: canonical decomposition of random process, random process forecast, joint linear filtration and extrapolation method, optimal method of consistent extrapolation.

2010 MSC: $62 \mathrm{P} 30$

DOI: $10.23939 / \mathrm{mmc} 2021.02 .157$

\section{Introduction}

The need for effective intelligence and combat operations in the East of Ukraine contributes to the active introduction of advanced technologies in the development of aviation [1-3]. The level of flight safety and the ability to perform a set task are determined by many characteristics [4-7]. The wide variety of situations that arise in thecourse of control procedure, and the need for prompt adoption of decisions compliant with various quality requirements, necessitate the comprehensive use of a rich armory of mathematical models and methods [8-11].

The development of information technology entails an increase in the capacity of computer systems. This makes it possible to introduce the prediction of random processes widely and in all fields of science [12-16]. The methods that previously could not be applied due to computational constraints are now being widely adopted [17-21]. Such methods include the forecasting based on canonical decomposition of vector random process [22-24]. The application of such methods provides an ample opportunity to obtain prognosis for complex and interdependent processes.

This article considers the improvement of the linear filtration and extrapolation method of the vector random process for the task of predicting the vector random process based on an example of predicting an aircraft trajectory at the approach stage. This method is based on the canonical decomposition of the vector random process, and the forming of a mixed sequence of its components. This would improve the accuracy of the random process prediction by $1.6-2$ times. 
The sources [22-24] contain a consideration of the method of compatible linear filtration and extrapolation based on complete a priori information about the process $(Z(t), X(t))$. In the framework of this method the information about the random process $(Z(t), X(t))$ used in full scope, but this extrapolator filter does not provide an absolute minimum of the mean square of the prediction error. This process is optimal for measurement results $\stackrel{\circ}{z}(\mu), \mu=\overline{1, k}$ but not for assessments $\stackrel{\hat{o}}{x}(\mu), \mu=\overline{1, k}$. The uncorrelated error of random processes $\stackrel{\circ}{z}(\mu)$ and $\stackrel{\hat{o}}{x}(\mu), \mu=\overline{1, k}$ causes the mismatch of the method of compatible linear filtration and extrapolation in the implementation of the random process $X(t)$. The elimination of this mismatch will further reduce the extrapolation error. This necessitates the further development and improvement of the methods of compatible linear filtration and extrapolation applied to solve the problem of predicting the motion of the aircraft at the approach stage.

\section{Problem statement}

We create a "mixed" random sequence $\left\{\stackrel{\circ}{X^{\prime}}\right\}=\{\stackrel{\hat{o}}{X}(1), \stackrel{\hat{o}}{X}(2), \ldots, \stackrel{\hat{\circ}}{X}(k), \stackrel{\circ}{X}(i=k+1), \ldots, \stackrel{\circ}{X}(I)\}$, which combines the data for the $i \leqslant k$, and the data for the process $\stackrel{\circ}{X}(t)$ for $k<i \leqslant I$. In case with this sequence, the standard method can be used to obtain the canonical decomposition, which is the basis for creation of the prediction method.

Now, we shall consider the peculiarities pertaining to the process of creating such method for the increasing $k$.

In the case $k=1$, the random value $\stackrel{\hat{o}}{X}(1)$ (result of filtration multiplicity) is represented as follows:

$$
\stackrel{\hat{\circ}}{X}(1)=P_{1} \stackrel{\circ}{Z}(1) \text {. }
$$

In this expression the $P_{1}$ is the coefficient of optimal linear filtration, which is determined from the condition $M\left[|\stackrel{\circ}{X}(1)-\stackrel{\hat{o}}{X}(2)|^{2}\right]=\min$.

The properties of the value $\hat{\hat{O}}^{\prime}(1)$ are determined by the ratios:

$$
\begin{aligned}
D_{\hat{x}}(1) & =P_{1}^{2} D_{z}(1), \\
R_{\hat{x}, x}(1, i) & =P_{1} R_{z x}(1, i), \quad i=\overline{2, I} .
\end{aligned}
$$

Now, we shall replace the random value $\stackrel{\circ}{X}(1)$ in the sequence $\{\stackrel{\circ}{X}\}=X(i), i=\overline{1, I}$ by the random value $\hat{o}^{\circ}(1)$. This results in the sequence $\{\stackrel{\circ}{X} 1\}$ whose canonical decomposition is represented in the standard manner

$$
\stackrel{\circ}{X} 1(i)=\sum_{\nu=1}^{i} Q_{\nu}^{(1)} \varsigma_{\nu}^{(1)}, \quad i=\overline{1, I} .
$$

\section{Method of optimal extrapolation for centered implementation of random process}

The canonical decomposition (4) can be used as basis to implement the standard method of optimal extrapolation of centered implementation of the random process $X(t)$ in the presence of the first known value $\stackrel{\circ}{z}(1)$

$$
m_{\stackrel{\hat{x}}{(1)}}^{(1)}(i) \stackrel{\hat{\jmath}}{x}(i) \varsigma_{1}^{(1)}(i)=\stackrel{\circ}{z}(1) P_{1} \varsigma_{1}^{(1)}(i), \quad i=\overline{2, I} .
$$

$\varsigma_{1}^{(1)}(i)$ is determined by the ratio:

$$
\varsigma_{1}^{(1)}(i)=\frac{1}{D_{Q_{1}^{(1)}}} R_{\hat{x}, x}(1, i), \quad i=\overline{1, I},
$$

where $D_{Q_{1}^{(1)}}=D_{\hat{x}}(1)$. 
Accordingly, in the case with $k=1$ the task is solved, since the above mismatch has been eliminated.

Now, we shall apply the idea of matched joint filtration and extrapolation for $k=2$. In this case, the random value $\hat{\hat{O}}^{\mathrm{X}}(2)$ is formed in the standard manner as follows:

$$
\stackrel{\hat{o}}{X}(2)=\left(1-P_{2}\right) m_{\hat{x}}^{(1)}(2)+P_{2} \stackrel{\circ}{Z}(2)
$$

Accordingly, the sequence is determined completely as follows:

$$
\{\stackrel{\circ}{X} 2\}=\{\stackrel{\hat{\circ}}{X}(1), \stackrel{\hat{\circ}}{X}(2), \stackrel{\circ}{X}(3), \ldots, \stackrel{\circ}{X}(I)\} .
$$

In case with the sequence $\{\stackrel{\circ}{X} 2\}$ the following canonical decomposition can be obtained:

$$
\stackrel{\circ}{X} 2(i)=\sum_{\nu=1}^{i} Q_{\nu}^{(2)} \varsigma_{\nu}^{(2)}, \quad i=\overline{1, I} .
$$

The method of optimal linear filtration and extrapolation is formed based on the canonical decomposition (8) is represented as follows, under presence of the initial two measurements $\stackrel{\circ}{z}(\mu), \mu=\overline{1,2}$ :

$$
\begin{aligned}
m_{\hat{o}}^{(2)}(i)=\stackrel{\hat{o}}{x}(1) & {\left[\varsigma_{1}^{(2)}(i)-\varsigma_{1}^{(2)}(2) \varsigma_{2}^{(2)}(i)\right]+\stackrel{\hat{o}}{x}(2) \varsigma_{2}^{(2)}(i) } \\
& =\stackrel{\circ}{z}(1) P_{1}\left[\varsigma_{1}^{(2)}(i)-\varsigma_{1}^{(2)}(2) \varsigma_{2}^{(2)}(i)+\left(1-P_{2}\right) \varsigma_{1}^{(2)}(i) \varsigma_{2}^{(2)}(i)\right]+\stackrel{\circ}{z}(2) P_{2} \varsigma_{2}^{(2)}(i), \quad i=\overline{3, I} .
\end{aligned}
$$

In this case, the $\varsigma_{1}^{(1)}(2)$ is determined as the ratio (6), while the expressions for $\varsigma_{\nu}^{(2)}(i), \nu=\overline{1,2}, i=\overline{3, I}$, $\varsigma_{1}^{(2)}(2)$ are represented as follows:

where $D_{Q_{1}^{(2)}}(i)=D_{\hat{x}}(1)$;

$$
\begin{aligned}
& \varsigma_{1}^{(2)}(2)=\frac{R_{\hat{x}}(1,2)}{D_{Q_{1}^{(2)}}}, \\
& \varsigma_{1}^{(2)}(I)=\frac{R_{\hat{x}}(1, i)}{D_{Q_{1}^{(i)}}}, \quad i=\overline{3, I},
\end{aligned}
$$

$$
\varsigma_{2}^{(2)}(i)=\frac{1}{D_{Q_{2}^{(2)}}}\left[R_{\hat{x} x}(2, i)-D_{Q_{1}^{(2)}} \varsigma_{1}^{(2)}(2) \varsigma_{1}^{(2)}(i)\right], \quad i=\overline{3, I}
$$

where $D_{Q_{1}^{(2)}}=D_{\hat{x}}(2)-D_{Q_{1}^{(2)}}\left[\varsigma_{1}^{(2)}(i)\right]^{2}$.

The analysis of expressions (7) and (12) shows that the coordinate functions $\varsigma_{1}^{(1)}(i)$ and $\varsigma_{1}^{(2)}(i)$ appear to be coinciding for $i=\overline{3, I}$. This is explained by the following facts. First, at the moments $i=1$ and $i=\overline{3, I}$ the sequence $\{\stackrel{\circ}{X} 2\}$ has the same properties as the sequence $\{\stackrel{\circ}{X} 1\}$. Second, the coordinate functions $\varsigma_{1}^{(1)}(i)$ and $\varsigma_{1}^{(2)}(i)$ are formed primarily in the canonical decompositions (5) and (9). It is understood that for the same reason the functions $\varsigma_{\nu}^{(2)}(i), \nu=\overline{1,2}, i=\overline{4, I}, \varsigma_{1}^{(2)}(2)$ of the decomposition (9) coincide with the appropriate coordinate functions of the canonical decomposition of the sequence $\{\stackrel{\circ}{X} 3\}=\{\stackrel{\hat{o}}{X}(1), \stackrel{\hat{o}}{X}(2), \stackrel{\hat{o}}{X}(3), X(4), \ldots, X(I)\}$, that is formed at the next stage of filtration,

$$
C \nu_{\mu}^{(k)}(i)=\left\{\begin{array}{l}
C \nu_{\mu}^{(k-1)}(i)-C \nu_{\mu}^{(k-1)}(k) \varsigma_{k}^{(\nu)}(i), \quad \mu<k, \\
\varsigma_{k}^{(\nu)}(i), \quad \mu=k .
\end{array}\right.
$$

Based on the above designation, the method (9) is then represented as follows:

$$
m_{\hat{\grave{x}}}^{(2)}(i)=\stackrel{\circ}{z}(1) P 1\left[C 2_{1}^{(2)}(i)+\left(1-P_{2}\right) C 1_{1}^{(1)}(2) C 2_{2}^{(2)}(i)\right]+z(2) P_{2} C 2_{2}^{(2)}(i), \quad i=\overline{3, I} .
$$


The resultant method of prediction creates the basis for formation of the random value $\stackrel{\hat{o}}{X}^{(3)}$

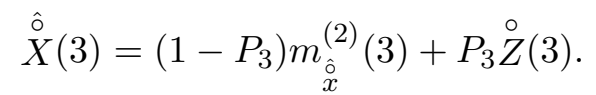

The canonical decomposition of the sequence $\{\stackrel{\circ}{X} 3\}=\left\{\stackrel{\hat{\circ}}{X}(1), \stackrel{\hat{o}}{X}(2), \stackrel{\hat{o}}{X}^{(3)}, X(4), \ldots, X(I)\right\}$ is represented as follows:

$$
X 3(i)=\sum_{\nu=1}^{i} Q_{\nu}^{(3)} \varsigma_{\nu}^{(3)}(i), \quad i=\overline{1, I} .
$$

The ratio necessary to determine the coordinate functions $\varsigma_{\nu}^{(3)}(\mu), \nu=\overline{1,3}, \mu=\overline{\nu, 3}, i=\overline{4, I}$, which are used to form the prediction method, under the presence of $\stackrel{\circ}{z}(\mu), \mu=\overline{1,3}$, and with account of the properties of the elements of the canonical decomposition (4) and (8), is represented as follows:

$$
\begin{aligned}
& \varsigma_{\nu}^{(3)}(i)=\left\{\begin{array}{l}
\varsigma_{\nu}^{(2)}(i) \quad \text { for } \quad \nu=\overline{1,2}, \quad i=\overline{\nu, I}, \quad i \neq 3, \\
\frac{1}{D_{Q_{\nu}^{(3)}}}\left[R_{\hat{x}}(\nu, i)-\sum_{j=1}^{\nu-1} D_{Q_{j}^{(3)}} \varsigma_{j}^{(3)}(\nu) \varsigma_{j}^{(3)}(i)\right] \quad \text { for } \quad \nu=\overline{1,2}, \quad i=3, \\
\frac{1}{D_{Q_{\nu}^{(3)}}}\left[R_{x \hat{x}}(\nu, i)-\sum_{j=1}^{\nu-1} D_{Q_{j}^{(3)}} \varsigma_{j}^{(3)}(\nu) \varsigma_{j}^{(3)}(i)\right] \quad \text { for } \quad \nu=3, \quad i=\overline{4, I} ;
\end{array}\right. \\
& D_{Q_{\nu}^{(3)}}=\left\{\begin{array}{l}
D_{Q_{\nu}^{(2)}}, \quad \nu=\overline{1,2} \\
D_{\hat{x}}(3)-\sum_{j=1}^{\nu-1} D_{Q_{j}^{(3)}}\left(\varsigma_{j}^{(3)}(3)\right)^{2}, \quad \nu=3 .
\end{array}\right.
\end{aligned}
$$

As it has been presupposed, the coordinate functions of the canonical decomposition (18) necessary for the prediction method at $(k=3)$ differ from the relevant coordinate functions of the decomposition (18) only for the moment $i=3$, which determines the difference between the sequences $\{\stackrel{\circ}{X} 2\}$ and $\{\stackrel{\circ}{X} 3\}$.

\section{Optimal method of joint filtration and extrapolation}

Having completed the conversions analogous to those mentioned before, we shall obtain the optimal method of joint filtration and extrapolation, under the presence of the measurements $\stackrel{\circ}{z}(\mu), \mu=\overline{1,3}$

$$
\begin{aligned}
m_{\hat{\mathrm{o}}}^{(3)}(i)=\stackrel{\circ}{z}(1) P 1\left[C 3_{1}^{(3)}(i)\right. & +\left(1-P_{2}\right) C 1_{1}^{(1)}(2) C 3_{2}^{(2)}(i) \\
+ & {\left.\left[C 2_{1}^{(2)}(3)+C 1_{1}^{(1)}(2)\left(1-P_{2}\right) C 2_{2}^{(2)}(3)\right]\left(1-P_{3}\right) C 3_{3}^{(3)}(i)\right] } \\
& +\stackrel{\circ}{z}(2) P 2\left[C 3_{2}^{(3)}(i)+C 2_{2}^{(2)}(3)\left(1-P P_{3}\right) C 3_{3}^{(3)}(i)\right]+\stackrel{\circ}{z}(3) P P_{3} C 3_{3}^{(3)}(i) .
\end{aligned}
$$

The recurrent nature of the ratios (14), (15) and (20) allows us to make up the equation that describes the functioning of the optimal linear extrapolating filter for the arbitrary number $k<I$ of the results of previous measurements $\stackrel{\circ}{z}(\mu), \mu=\overline{1,3}$

$$
m_{\hat{x}}^{(k)}=m_{x}(i)+\sum_{\mu=1}^{k} \stackrel{\circ}{ }^{\prime}(\mu) P_{\mu} L_{\mu}^{(k)}(i), \quad i=\overline{k+1, I} .
$$

In this case, the weight functions $L_{\mu}^{(k)}(i), \mu=\overline{1, k}, i=\overline{k+1, I}$ are determined by the ratio:

$$
L_{\mu}^{(k)}(i)=\sum_{j=\mu}^{k} N_{\mu}(j) C k_{j}^{(k-1)}(i), \quad \mu=\overline{1, k}, \quad i=\overline{k+1, I} .
$$


In turn, the $C k_{j}^{(k-1)}(i)$ is calculated by use of the expression (13), while the weights $N_{\mu}(j)$ are recognized as the recurrent ratios:

$$
N_{\mu}(j)=\left\{\begin{array}{l}
1, \quad j=\mu ; \\
\sum_{\nu=\mu}^{j-1} N_{\mu}(\nu) C j-1_{\nu}^{(j-1)}(j)\left(1-P_{j}\right), \quad j=\overline{\mu+1, k} .
\end{array}\right.
$$

The coordinate functions $\varsigma_{\nu}^{(\mu)}(i), \mu=\overline{1, k}, \nu=\overline{1, k}, i=\overline{\nu, I}$, which are elements of the canonical decompositions of the sequences $\left\{\stackrel{\hat{O}}{X}_{\mu}\right\}=\left\{\stackrel{\hat{O}}{X}^{(1)}\left(1, \ldots, \stackrel{\hat{O}}{X}(\mu), \stackrel{\circ}{X}^{\prime}(i=\mu+1), \ldots, \stackrel{\circ}{X}^{\prime}(I)\right\}, \mu=\overline{1, k}\right.$, are used as the source information for the expression $L_{\mu}^{(k)}(i)$. The said coordinate functions are determined by the recurrent ratios as follows:

$$
\begin{aligned}
& \varsigma_{\nu}^{(\mu)}(i)=\left\{\begin{array}{l}
\varsigma_{\nu}^{(\mu-1)}(i), \quad \nu=\overline{1, \mu-1}, \quad i=\overline{\nu, I}, \quad i \neq \mu \\
\frac{1}{D_{Q_{\nu}^{(\mu)}}}\left[R_{\hat{x}}(\nu, i)-\sum_{j=1}^{\nu-1} D_{Q_{j}^{(\mu)}} \varsigma_{j}^{(\mu)}(\nu) \varsigma_{j}^{(\mu)}(i)\right], \quad \nu=\overline{1, \mu-1}, \quad i=\mu \\
\frac{1}{D_{Q_{\nu}^{(\mu)}}}\left[R_{x \hat{x}}(\nu, i)-\sum_{j=1}^{\nu-1} D_{Q_{j}^{(\mu)}} \varsigma_{j}^{(\mu)}(\nu) \varsigma_{j}^{(\mu)}(i)\right], \quad \nu=\mu, \quad i=\overline{\mu+1, I}
\end{array}\right. \\
& D_{Q_{\nu}^{(\mu)}}=\left\{\begin{array}{l}
D_{Q_{\nu}^{(\mu-1)}, \quad \nu=\overline{1, \mu-1}} \\
D_{\hat{x}}(\mu)-\sum_{j=1}^{\nu-1} D_{Q_{j}^{(\mu)}\left(\varsigma_{j}^{(\mu)}(\mu)\right)^{2}, \quad \nu=\mu .} .
\end{array}\right.
\end{aligned}
$$

The expressions for the definition $R_{\hat{x}}(\nu, \mu), R_{\hat{x} x}(\nu, i), D_{\hat{x}}(i)$ based on use of $(12)$ are represented as follows:

$$
\begin{aligned}
& D_{\hat{x}}(i)=\left(1-P_{i}\right)^{2} \sum_{l=1}^{i-1} \sum_{j=1}^{i-1} R_{z}(l, j) P_{l} P_{j} L_{l}^{(i-1)}(i) L_{j}^{(i-1)}(i)+P_{i}^{2} D_{z}(i) \\
& +\left(1-P_{i}\right) P_{i} \sum_{\nu=1}^{i-1} R_{z}(\nu, i) P_{\nu} P_{i} L_{\nu}^{(i-1)}(i), \quad i=\overline{1, k} \\
& R_{\hat{x}}(\nu, \mu)=\left(1-P_{\mu}\right)\left(1-P_{\nu}\right) \sum_{l=1}^{\nu-1} \sum_{j=1}^{\mu-1} R_{z}(l, j) P_{l} P_{j} L_{l}^{(\nu-1)}(\nu) L_{j}^{(\mu-1)}(\mu) \\
& +\left(1-P_{\nu}\right) P_{\mu} \sum_{j=1}^{\nu-1} R_{z}(j, \mu) P_{j} L_{j}^{(\nu-1)}(\nu)+\left(1-P_{\mu}\right) P_{\nu} \sum_{j=1}^{\mu-1} R_{z}(j, \nu) P_{j} L_{j}^{(\mu-1)}(\mu) \\
& +P_{\nu} P_{\mu} R_{z}(\nu, \mu), \quad \nu, \mu=\overline{1, k}, \\
& R_{\hat{x}, x}(\mu, i)=\left(1-P_{\mu}\right) \sum_{j=1}^{\mu-1} R_{z x}(j, i) P_{j} L_{j}^{(\mu-1)}(\mu)+P_{\mu} R_{z x}(\mu, i), \quad \mu=\overline{1, k}, \quad i=\overline{\mu+1, I} .
\end{aligned}
$$

The expression for the average squared error of filtration based on use of the ratio (18) is represented as follows:

$$
E_{\Phi}(k)=M\left[\left|\left(1-P_{k}\right) \sum_{\mu=1}^{k-1} \stackrel{\circ}{Z}(\mu) P(\mu) L_{\mu}^{(k-1)}(k)+P_{\mu} \stackrel{\circ}{Z}(k)-\stackrel{\circ}{X}(k)\right|^{2}\right] .
$$

Having differentiated this expression based on $P_{k}$ and solved a relevant equation, we shall obtain the 
expression that can be used to calculate the optimal value $P_{k}$ :

$$
P_{k}=\frac{R 1_{k}+R 2_{k}-R 3_{k}}{R 1_{k}+R 2_{k}-2 R 3_{k}+D_{y}(k)}
$$

where

$$
\begin{gathered}
R 1_{k}=D_{x}(k)-2 \sum_{\mu=1}^{k-1} R_{x}(\mu, k) L_{\mu}^{(k-1)}(k) P_{\mu}-2 \sum_{\mu=1}^{k-1} R_{x y}(\mu, k) L_{\mu}^{(k-1)}(k) P_{\mu} \\
+\sum_{\mu=1}^{k-1} \sum_{\nu=1}^{k-1} R_{x}(\mu, \nu) L_{\mu}^{(k-1)}(k) P_{\mu} L_{\nu}^{(k-1)}(k) P_{\nu} \\
R 2_{k}=\sum_{\mu=1}^{k-1} \sum_{\nu=1}^{k-1} R_{x}(\mu, \nu) L_{\mu}^{(k-1)}(k) P_{\mu} L_{\nu}^{(k-1)}(k) P_{\nu} \\
R 3_{k}=\sum_{\mu=1}^{k-1} R_{y}(\mu, k) L_{\mu}^{(k-1)}(k) P_{\mu} .
\end{gathered}
$$

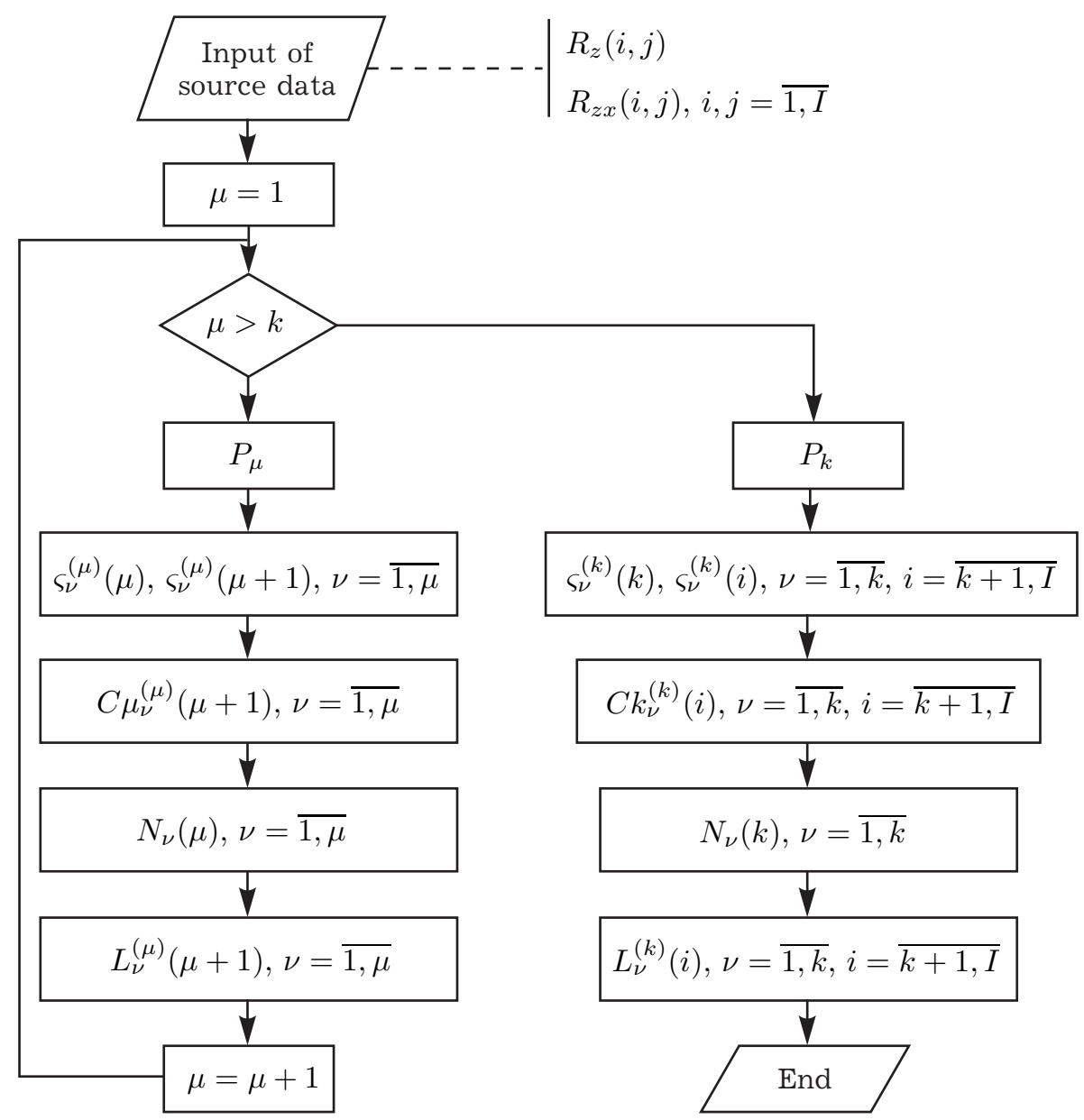

Fig. 1. Block diagram of procedure for determination of weight functions. 
The procedure used to determine the weight functions $L_{\mu}^{(k)}(k), \mu=\overline{1, k}, i=\overline{k+1, I}$, (Fig. 1) and filtration coefficients $P_{\mu}, \mu=\overline{1, k}$ is fairly cumbersome. This is due to the fact that, firstly, the calculation of such coefficients is done with account of all previous history of the processes $X(t)$ and $Y(t)$ in the framework of the ideas about the nature of such processes; and, secondly, the calculation of $L_{\mu}^{(k)}(k), \mu=\overline{1, k}, i=\overline{k+1, I}$ and $P_{\mu}, \mu=\overline{1, k}$ is done with account of the property of random values $\hat{\circ}(\mu), \mu=\overline{1, k}$.

It should be kept in mind, however, that the said parameters of the method (14) can be calculated in advance. This also applies to the previous methods of prediction presented herein. Accordingly, the method (14) does not impose any restrictions with regard to calculation, and can be implemented in present-day onboard computation complexes.

The error of single extrapolation when using the method (14) is represented as follows:

$$
\sigma_{\hat{x}}^{(k)}(i)=m_{\hat{x}}^{(k)}(i)-m_{x}^{(k)}(i)-\sum_{\nu=k+1}^{i} V_{\nu} \varphi_{\nu}(i), \quad i=\overline{k+1, I} .
$$

As before, the variance of extrapolation is equal to the a posteriori variance, while the expression for the conditional systematic error of the single extrapolation is represented as follows:

$$
\begin{gathered}
S_{\hat{x}}^{(k)}(i / z(\mu), \mu=\overline{1, k})=\sum_{\mu=1}^{k} \stackrel{\circ}{x}(\mu)\left(P_{\mu} L_{\mu}^{(k)}(i)-f_{\mu}^{(k)}(i)\right)+\sum_{\mu=1}^{k} \stackrel{\circ}{y}(\mu) P_{\mu} L_{\mu}^{(k)}(i), \quad k<I, \quad i=\overline{k+1, I}, \\
S_{\hat{x}}^{(k)}(i)=0, \quad i=\overline{k+1, I} .
\end{gathered}
$$

Therefore, it can be concluded that the systematic error of extrapolation does not occur when using the method (14).

The average squared error of extrapolation is represented as follows:

$$
\begin{aligned}
E_{\hat{x}}^{(k)}(i) & =\sum_{\mu=1}^{k} \sum_{\nu=1}^{k} R_{y}(\mu, \nu) P_{\mu} P_{\nu} L_{\mu}^{(k)}(i) L_{\nu}^{(k)}(i)+\sum_{\mu=1}^{k} \sum_{\nu=1}^{k} R_{x y}(\mu, \nu)\left(P_{\mu} L_{\mu}^{(k)}(i)-f_{\mu}^{(k)}(i)\right) P_{\nu} L_{\nu}^{(k)}(i) \\
& +\sum_{\mu=1}^{k} \sum_{\nu=1}^{k} R_{x}(\mu, \nu)\left(P_{\mu} L_{\mu}^{(k)}(i)-f_{\mu}^{(k)}(i)\right)\left(P_{\nu} L_{\nu}^{(k)}(i)-f_{\nu}^{(k)}(i)\right), \quad k<I, \quad i=\overline{k+1, I} .
\end{aligned}
$$

According to the above, we can deduce that the completed research resulted in the optimal method of matched extrapolation with pre-filtering of measurement errors, which does not impose any significant restrictions on the class of random processes that are predicted.

The extrapolating filter (14) in question is a generalization of all the scalar prediction methods considered in this article. The said scalar prediction methods follow from (14) as the partial cases, which correspond to the imposition of certain restrictions on the extrapolating filter (14). Thus, the method (14) is reduced to the form presented in (1) when the filtration and extrapolation operations are not matched. If the (14) is not included into the filtration operation $P_{\mu}, \mu=\overline{1, k}$, this method coincides with the generalized method of optimal linear extrapolation in the presence of measurement errors and complete a priori information.

\section{Numerical experiment}

The analysis of models and methods forprediction ofaircraft motion, which are implemented nowadays, showed that this problem is solved within the framework of fixed ideas about the nature of aircraft motion [25-28]. However, it should be noted that the modern aircraft have high maneuverability; 
accordingly, the motion can occur in critical situations and the physical trajectory of motion may not be taken be into account. This causes the need to develop methods for solving prediction problems with a broader scope of view. Therefore, the development of methods for matched linear filtration and extrapolation, and application of such methods in the tasks of predicting the motion of aircraft at the approach stage represent a fairly relevant and promising task.

We have performed practical calculations with use of the developed methodology on actual trajectories of landing of the Su-27 aircraft (Fig. 2), and have shown that the application of this methodology allows to increase the prediction accuracy by up to $1.61-2$ times. Furthermore, the application of this method yields an increase of time for decision-making by up to $50 \mathrm{~s}$ from the initial time frame of $7-10 \mathrm{~s}$.

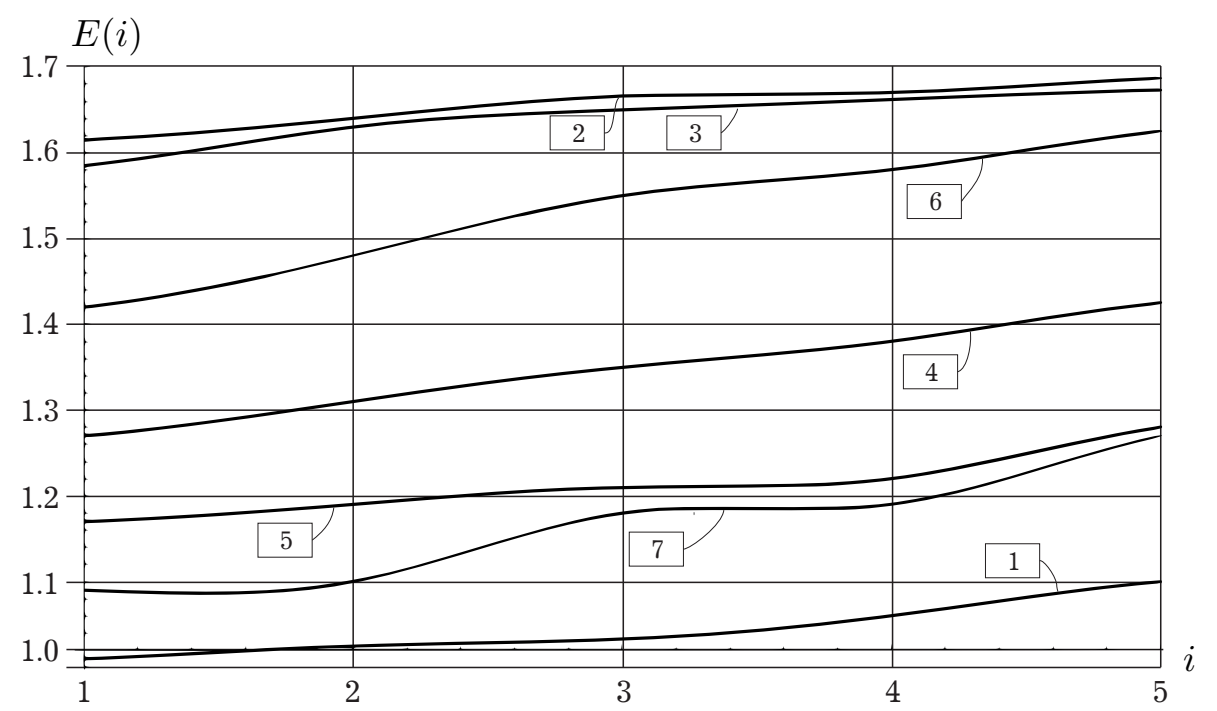

Fig. 2. Dependence of estimates of mean squares of total extrapolation error on prediction interval of methods presented in this paper.

Figure 2 shows the dependence of estimates of mean squares of the total extrapolation error on the prediction interval of the methods presented in this paper. Where:

1 is Perfect prediction;

2 is Minimum a priori information;

3 is Linear prediction with use of information on random measurement process;

4 is Two-dimensional canonical decomposition;

5 is Inclusion of linear filtration operation into prediction algorithm;

6 is Algorithm of joint linear filtration and extrapolation based on complete a priori information on process $(X, Z)$;

7 is Algorithm of linear filtration and extrapolation based on complete a priori information and creation of mixed sequence.

\section{Conclusion}

The methods of joint linear filtration and extrapolation considered herein do not impose any computational constraints. This will save computing resources and increase the speed of information processing. The numerical experiment has showed that the application of the proposed methodology will allow improvement of the accuracy of prediction and significant increase in the time for decision-making.

The results obtained herein confirm the availability of the chosen line of research for the theory and practice of vectorial random processes. It should be noted here that the methods considered herein 
may also be effective in the development and improvement of other types of complex military-technical systems requiring the prediction of system condition or process development.

[1] Zhengbing H., Mukhin V. Y., Kornaga Y. I., Herasymenko O. Y. Resource Management in a Distributed Computer System with Allowance for the Level of Trust to Computational Components. Cybernetics and Systems Analysis. 53, 312-322 (2017).

[2] Sushchenko O. A., Bezkorovayniy Y. M., Golytsin V. O. Processing of Redundant Information in Airborne Electronic Systems by means of Neural Networks. 2019 IEEE 39th International Conference on Electronics and Nanotechnology (ELNANO). 652-655 (2019).

[3] Bezkorovainyi Y. N., Sushchenko O. A. Improvement of UAV Positioning by Information of Inertial Sensors. 2018 IEEE 5th International Conference on Methods and Systems of Navigation and Motion Control (MSNMC). 123-126 (2018).

[4] Barabash O., Lukova-Chuiko N., Sobchuk V., Musienko A. Application of Petri Networks for Support of Functional Stability of Information Systems. 2018 IEEE 1st International Conference on System Analysis and Intelligent Computing (SAIC). 1-4 (2018).

[5] Mukhin V., Zavgorodnii V., Barabash O., Mykolaichuk R., Kornaga Y., Zavgorodnya A., Statkevych V. Method of restoring parameters of information objects in a unified information space based on computer networks. International Journal of Computer Network and Information Security. 12 (2), 11-21 (2020).

[6] Obidin D., Ardelyan V., Lukova-Chuiko N., Musienko A. Estimation of functional stability of special purpose networks located on vehicles. 2017 IEEE 4th International Conference Actual Problems of Unmanned Aerial Vehicles Developments (APUAVD). 167-170 (2017).

[7] Grechko V., Babenko T., Myrutenko L. Secure Software Developing Recommendations. 2019 IEEE International Scientific-Practical Conference Problems of Infocommunications, Science and Technology (PIC S\&T). 45-50 (2019).

[8] Barabash O., Shevchenko H., Dakhno N., Kravchenko Y., Olga L. Effectiveness of Targeting Informational Technology Application. 2020 IEEE 2nd International Conference on System Analysis \& Intelligent Computing (SAIC). 193-196 (2020).

[9] Prats'ovytyi M., Svynchuk O. Spread of Values of a Cantor-Type Fractal Continuous Nonmonotone Function. J. Math. Sci. 240, 342-357 (2019).

[10] Rokochinskiy A., Volk P., Kuzmych L., Turcheniuk V., Volk L., Dudnik A. Mathematical model of meteorological software for systematic flood control in the Carpathian region. 2019 IEEE International Conference on Advanced Trends in Information Theory ATIT. 143-148 (2019).

[11] Hu Z., Mukhin V., Kornaga Y., Herasymenko O., Mostoviy Y. The Analytical Model for Distributed Computer System Parameters Control Based on Multi-factoring Estimations. Journal of Network and Systems Management. 27, 351-365 (2019).

[12] Kravchenko Y., Leshchenko O., Dakhno N., Deinega V., Shevchenko H., Trush O. Intellectual fuzzy system air pollution control. 2020 IEEE 2nd International Conference on Advanced Trends in Information Theory (ATIT). 186-191 (2020).

[13] Leshchenko O., Trush O., Dakhno N., Dudnik A., Kazintseva K., Kovalenko O. Methods for predicting adjustments to the rates of modern "digital money". 2020 IEEE 2nd International Conference on Advanced Trends in Information Theory (ATIT). 222-226 (2020).

[14] Hnatiienko H., Kudin V., Onyshchenko A., Snytyuk V., Kruhlov A. Greenhouse Gas Emission Determination Based on the Pseudo-Base Matrix Method for Environmental Pollution Quotas Between Countries Allocation Problem. 2020 IEEE 2nd International Conference on System Analysis \& Intelligent Computing (SAIC). 1-8 (2020).

[15] Barabash O. V., Open'ko P. V., Kopiika O. V., Shevchenko H. V., Dakhno N. B. Target programming with multicriterial restrictions application to the defense budget optimization. Advances in Military Technology. 14 (2), 213-229 (2019).

[16] Kravchenko Y., Dakhno N., Leshchenko O., Tolstokorova A. Machine learning algorithms for predicting the results of COVID-19 coronavirus infection. CEUR Workshop Proceedings. 7th International Conference "Information Technology and Interactions". 2845, 371-381 (2021). 
[17] Mashkov O. A., Sobchuk V. V., Barabash O. V., Dakhno N. B., Shevchenko H. V., Maisak T. V. Improvement of variational-gradient method in dynamical systems of automated control for integro-differential models. Mathematical Modeling and Computing. 6 (2), 344-357 (2019).

[18] Barabash O. V., Musienko A. P., Sobchuk V. V., Lukova-Chuiko N. V., Svynchuk O. V. Distribution of Values of Cantor Type Fractal Functions with Specified Restrictions. Understanding Complex Systems. 433-455 (2021).

[19] Tmienova N., Snytyuk V. Method of Deformed Stars for Global Optimization. 2020 IEEE 2nd International Conference on System Analysis \& Intelligent Computing (SAIC). 1-4 (2020).

[20] Zhengbing H., Mukhin V. Y., Kornaga Y. I., Herasymenko O. Y. Resource Management in a Distributed Computer System with Allowance for the Level of Trust to Computational Components. Cybernetics and Systems Analysis. 53, 312-322 (2017).

[21] Pysarchuk O., Gizun A., Dudnik A., Griga V., Domkiv T., Gnatyuk S. Bifurcation Prediction Method for the Emergence and Development Dynamics of Information Conflicts in Cybernetic Space. CEUR Workshop Proceedings. 2019 International Workshop on Cyber Hygiene. 2654, 692-709 (2020).

[22] Kravchenko I. Yu. Forecasting mathematical model aircraft trajectory based on linear filtering and extrapolation stochastic process to mixed sequence its components. Information Processing Systems. 9 (116), 36-40 (2013).

[23] Kudritsky V. D. Prediction of the reliability of electronic devices. Technics. 156 (1973).

[24] Murasov R. K., Dziubenko Yu. A. Forecasting the state of complex systems in modern management systems and intelligent information systems. Collection of scientific works of Kyiv National University of Civil Engineering and Architecture. 7, 97-101 (2011).

[25] Gramajo G., Shankar P. Efficient Energy Constraint Based UAV Path Planning for Search and Coverage. International Journal of Aerospace Engineering. 2017, Article ID 8085623, 13 pages (2017).

[26] Mashkov O. A., Chumakevich V. A., Mamchur Yu. V., Kosenko V. R. The method of inverse problems of dynamics for the synthesis of a system of stabilization of the movement of a dynamic object on operatively programmable trajectories. Mathematical Modeling and Computing. 7 (1), 29-38 (2020).

[27] Savchenko V., Haidur H., Gakhov S., Lehominova S., Muzshanova T., Novikova I. Model of control in a uav group for hidden transmitters detection on the basis of local self-organization. International Journal of Advanced Trends in Computer Science and Engineering. 9 (4), 6167-6174 (2020).

[28] Guerriero F., Surace R., Loscrí V., Natalizio E. A multi-objective approach for unmanned aerial vehicle routing problem with soft time windows constraints. Applied Mathematical Modelling. 38 (3), 839-852 (2014). 


\title{
Оптимальний алгоритм прогнозу на основі сумісної лінійної фільтрації та екстраполяції
}

\author{
Машков О. А. ${ }^{1}$, Мурасов Р. К. ${ }^{2}$, Кравченко Ю. В. ${ }^{2}$, \\ Дахно Н. Б. ${ }^{2}$, Лещенко О. О. ${ }^{2}$, Труш О. В. ${ }^{2}$ \\ ${ }^{1}$ Державна екологічна академія післядипломної освіти та менеджменту, \\ вул. Митрополита Василя Липківсъкого, 35, корп. 2, 03035, Киї, Україна \\ ${ }^{2}$ Київсъкий національний університет імені Тараса Шевченка, \\ вул. Богдана Гаврилишина, 24, 04116, Київ, Украӥна,
}

Розглянуто методи оптимальної лінійної екстраполяції траєкторії польоту літального апарату, що забезпечують мінімум середнього квадрату похибки прогнозу за різного обсягу апріорної інформації. В основу досліджень покладено канонічне розкладання векторного випадкового процесу. Визначається, що розвиток сучасних технологій тягне за собою підвищення вимог до якості та точності управління, але існуючі методи лінійної екстраполяції в зв'язку з властивими обмеженнями на випадковий процес, що описують рух літальних апаратів, не забезпечують максимальну точність прогнозу. Це робить необхідним подальший розвиток та удосконалення методів екстраполяції траєкторії літальних апаратів. Особливість розроблених методів екстраполяції траєкторії літальних апаратів полягає в тому, що дані методи в межах кореляційної моделі дозволяють повністю врахувати властивості реального випадкового процесу, що описує рух літального апарату на етапі заходу на посадку. У зв'язку з цим забезпечується максимально можлива точність лінійної екстраполяції за різноманітного стану інформаційного забезпечення. Розглянуті методи дозволяють підвищити безпеку польотів та ефективність застосування авіації. Це дає можливість розглядати нові можливості літальних апаратів та інших складних технічних систем.

Ключові слова: канонічний розклад випадкового прочесу, прогнозування випадкових прочесів, метод спільної лінійної фільтрацї та екстраполячіӥ, оптимальний метод узгодженої екстраполяиії. 